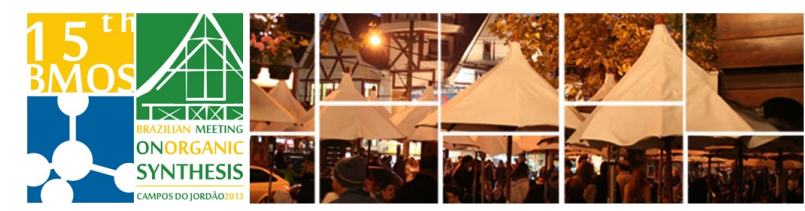

\title{
Coumarins from Free ortho-Hydroxy Cinnamates by Heck- Matsuda Arylations and their Application in the Total Synthesis of $(R)$-Tolterodine
}

\author{
${ }^{1}$ Daniela Aline Barancelli, ${ }^{2}$ Airton G. Salles Jr., ${ }^{3}$ Jason G. Taylor, ${ }^{2}$ Carlos Roque D. \\ Correia* \\ ${ }^{1}$ Universidade Tecnológica Federal do Paraná, UTFPR, Campus Campo Mourão, CEP. 87301-899, Campo \\ Mourão, Paraná, Brazil. \\ ${ }^{2}$ Instituto de Química, Universidade Estadual de Campinas, UNICAMP, C.P. 6154, CEP. 13084-971, \\ Campinas, São Paulo, Brazil. \\ ${ }^{3}$ Departamento de Química, ICEB, Universidade Federal de Ouro Preto, UFOP- Campus Universitário Morro \\ do Cruzeiro, 35400-000, Ouro Preto-MG, Brazil. \\ *roque@iqm.unicamp.br \\ Coumarins, Heck-Matsuda reaction, (R)-Tolterodine.
}

\section{INTRODUCTION}

Arylation methods are among the most important reaction types in organic synthesis. ${ }^{1}$ In recent years, our group and others have been exploring the palladium-catalyzed coupling of arenediazonium salts to olefins (Heck-Matsuda reaction) as a convenient method to obtain arylated and diarylated compounds of biological and medicinal interest. ${ }^{2}$ In this context, coumarins might be considered representative diarylated species of great interest due to their biological properties. ${ }^{3}$

\section{RESULTS AND DISCUSSION}

In this work, we describe a method for the synthesis of 4-aryl-coumarins 3 from free o-hydroxy-cinnamate ester derivatives 1 and the arenediazonium salts 2 via a tandem Heck-Matsuda cyclisation procedure under mild conditions. Many aryldiazonium salts possessing electron-neutral, electron-donating (ED), and electron withdrawing groups (EWG) were welltolerated under the reaction conditions (Scheme 1). ${ }^{4}$ The prevalence of the Heck coupling over the wellknown diazonium coupling, leading to azo dyes, is striking since the diazonium coupling is a very facile base-catalyzed process.

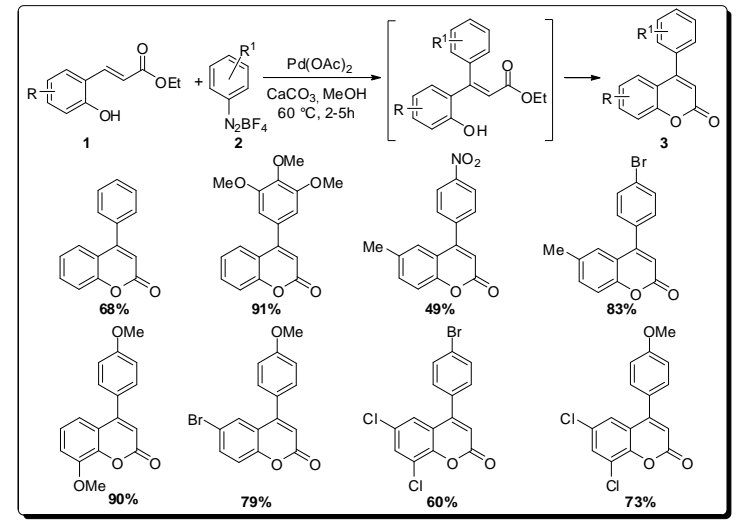

Scheme 1. Synthesis of 4-aryl-coumarins via tandem Heck-Matsuda arylation/cyclisation.

$15^{\text {th }}$ Brazilian Meeting on Organic Synthesis $-15^{\text {th }}$
After this, the generality of this new Heck-Matsuda protocol was demonstrated by a concise and enantioselective total synthesis of $(R)$-tolterodine, an antimuscarinic drug used in the treatment of urinary incontinence ${ }^{5}$ (Scheme 2).

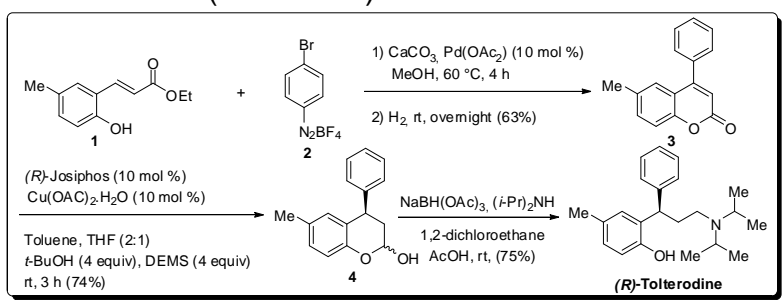

Scheme 2. Synthesis of $(R)$-tolterodine.

\section{CONCLUSION}

In summary, we have described an efficient, mild, and operationally simple method for the synthesis of 4-aryl-coumarins from free o-hydroxy-cinnamate ester derivatives via a tandem Heck arylation/cyclisation employing arenediazonium salts under palladium catalysis and aerobic conditions. Furthermore, the 6-methyl-4-phenyl-coumarin obtained in the current protocol was used as an intermediate for a concise (4 steps) asymmetric total synthesis of $(R)$-tolterodine in $30 \%$ overall yield and $98 \%$ ee.

\section{ACKNOWLEDGEMENTS}

We thank the Research Supporting Foundation of the State of São Paulo (FAPESP), Brazilian National Research Council (CNPQ) and Foundation Araucária for financial support and fellowships.

\section{REFERENCES}

${ }^{1}$ Alberico, D.; Scott, M. E.; Lautens, M. Chem. Rev. 2007, 107, 174.

2 Taylor, J. G.; Moro, A.V.; Correia, C. R. D. Eur. J. Org. Chem. 2011 1403. (b) Felpin, F-X.; Nassar-Hardy, L.; Callonnec, F. L.; Fouquet, E. Tetrahedron 2011, 67, 2815.

${ }^{3}$ Cooke, D.; O'Kennedy R. Anal. Biochem. 1999, 274, 188. b) Budzisz, E.; Brzezinska, E.; Krajewska, U.; Rozalski, M. Eur. J. Med. Chem. 2003, 38, 597.

${ }^{4}$ Barancelli, D. A.; Salles, A. G.; Taylor, J. G.; Correia, C. R. D. Org. Lett 2012, 14, 6036

${ }^{5}$ Wefer, J.; Truss, M. C.; Jonas, U. World J. Urol. 2001, 19, 312 